\section{Assessment of Oxygen Saturation Using Pulse Oximetry in Patients with Steady State HbSS}

\section{Abstract}

Background: The exact consequence of hypoxemia SCA is unclear, however, many studies have shown haemoglobin desaturation is common in patient with SCA even at steady state, and may predispose to several complications including pulmonary hypertension, stroke and acute chest syndrome. Therefore, detection of hypoxemia is important in patients with SCA.

Objectives: We sought to compare $\mathrm{SpO}_{2}$ of patients with $\mathrm{HbSS}$ in steady state and healthy individuals with $\mathrm{HbAA}$ genotype; and to determine the prevalence of hypoxemia amongst $\mathrm{HbSS}$ patients during steady state.

Materials and Methods: This is a prospective cross-sectional study involving ninety three adults with SCA in steady state and forty-eight healthy age and sex matched $\mathrm{HbAA}$ participants as controls. The oxygen saturation was recorded using a finger pulse oximeter (Suaoki, Model FS20A).

Results: The HbSS patients had a significantly lower mean $\mathrm{SpO}_{2}$ of $95.5 \%$ ( 4.1) compared to $99.06 \%$ ( 1.14$)$ for the healthy HbAA group $(p=0.0001)$. Male and female $\mathrm{HbSS}$ patients had a comparable $\mathrm{SpO}_{2}(95.8 \%$ vs $96.1 \%, \mathrm{p}=0.610)$. Similarly, mean $\mathrm{SpO}_{2}$ was similar in male and female $\mathrm{HbAA}$ group $(\mathrm{p}=0.258)$. The prevalence of hypoxemia among the $\mathrm{HbSS}$ patients was $30.25 \%$ compared to $2.7 \%$ amongst the $\mathrm{HbAA}$. The lowest $\mathrm{SpO}_{2}$ recorded among the $\mathrm{HbSS}$ patients was $88 \%$.

Conclusion: The prevalence of hypoxemia in steady state HbSS patients was high. This finding underscores the importance of monitoring HbSS patients for prompt detection of hypoxemia, and to institute therapy where necessary to prevent complications including pulmonary hypertension and cerebrovascular disease.

Keywords: Hypoxemia; Pulse oximetry; Sickle cell anaemia

Received: May 14, 2018; Accepted: May 31, 2018; Published: June 05, 2018
Ladu Al ${ }^{1,2 *}$, Abba AM ${ }^{1,2}$, Bukar AA ${ }^{1,2}$, Abulfathi FA ${ }^{1}$, Kundili ${ }^{1}$, Talba HA ${ }^{1}$, Abba Kawu $Y^{1}$, Tukur RA ${ }^{1}$ and Mohammad $\mathbf{Y}^{1}$

1 Department of Haematology and Blood Transfusion, University of Maiduguri Teaching Hospital, Maiduguri, Borno State, Nigeria

2 College of Medical Science, University of Maiduguri, Maiduguri, Borno State, Nigeria

*Corresponding author: Ladu-AI

” adamaisahladu@gmail.com

Department of Haematology and Blood transfusion, University of Maiduguri Teaching Hospital, PMB-1069, Maiduguri, Borno State, Nigeria.

Tel: +234803772013

Citation: Ladu Al, Abba AM, Bukar AA, Abulfathi FA, Kundili Y, et al. (2018) Assessment of Oxygen Saturation Using Pulse Oximetry in Patients with Steady State HbSS. Ann Clin Lab Res. Vol.6 No.2: 237

\section{Introduction}

The lungs are a major site of involvement in patients with sickle cell disease $(S C D)$, with both acute and chronic pulmonary complications commonly reported, and associated with increased mortality $[1,2]$. Sickle cell chronic lung disease presumably results from recurrent episodes of pulmonary infarction and infection. It is characterized by reduced lung luscency, abnormal pulmonary function, and in its severe form, pulmonary hypertension [1,3]. Moderate to severe pulmonary function impairment can results in hypoxemia, which may initiate or exacerbate vasculopathy [4]. There are reports of increased risk for central nervous system events with hypoxemia, whereas, higher oxygen saturations
$\left(\mathrm{SpO}_{2}\right)$ was associated with less frequent acute chest syndrome $[5,6]$. Many studies showed haemoglobin desaturation to be common in patient with sickle cell anaemia (SCA) even at steady state [7-9], and high prevalence of hypoxemia has been documented in children with SCA $[10,11]$. With improved care, the median survival of patients with SCA has risen, and therefore the prevalence of chronic organ diseases encountered in the adult population has also increased. In this study, $\mathrm{SpO}_{2}$ was assessed in adults with SCA using pulse oximetry, a widely utilized noninvasive technique. We sought to compare $\mathrm{SpO}_{2}$ of patients with $\mathrm{HbSS}$ in steady state and healthy individuals with $\mathrm{HbAA}$ genotype; and to determine the prevalence of of hypoxemia amongst HbSS patients during steady state. 


\section{Research Methodology}

Ninety three patients with steady state HBSS were evaluated during routine outpatient visits at the Haematology unit of the University of Maiduguri Teaching Hospital, from January through June 2017. Forty-eight healthy age and sex matched $\mathrm{HbAA}$ participants were used as controls. Oxygen saturation was recorded using a finger pulse oximeter (Suaoki, Model FS20A). This uses the principle of spectrophotometery and photoelectric plethysmography in determining oxygen saturation [12]. The appropriate sensor was placed on the right or left index finger and the values recorded after at least 2 minutes of stable $\mathrm{SpO}_{2}$, determined as regular pulsatile photoplethysmography signal apparent on the visual display of the oximeter. All measurements were made while the patient was breathing room air. Low oxygen saturation was defined as $\mathrm{SpO}_{2}$ less than $96 \%$, which predicts a $\mathrm{PaO}_{2}$ of less than $70 \mathrm{~mm} \mathrm{Hg}$ based on a normal oxyhaemoglobin curve [10]. The data was analyzed using the statistical package for social sciences version 20.0 (SPSS Chicago III USA.). Normality of data was tested using Kolmogorov-Smirnov test, and continuous variables expressed using means (SD) or proportions and compared using Student's t-test. A $p$ value of $<0.05$ was considered significant for all statistical analysis.

\section{Results}

The HbSS patients were made up of $36(38.7 \%)$ males and 57 (67.3\%) females, while HbAA controls comprised of 24 (50\%) males and 24 (50\%) females; with a mean age of 23.11 (6.03) years for the HbSS patients and 25.8 (6.19) years for the HbAA controls $(p=0.07)$. The pulse rates and $\mathrm{SpO}_{2}$ of $\mathrm{HbSS}$ patients and $\mathrm{HbAA}$ controls are illustrated in Table 1 . The HbSS patients had a significantly lower mean $\mathrm{SpO}_{2}$ of $95.5 \%$ (4.1) compared to $99.06 \%$ ( 1.14$)$ for the healthy HbAA group ( $p=0.0001)$. Male and female $\mathrm{HbSS}$ patients had a comparable $\mathrm{SpO}_{2}(95.8 \%$ vs. $96.1 \%$, $\mathrm{p}=0.610)$. Similarly, mean $\mathrm{SpO}_{2}$ was similar in male and female HbAA group ( $p=0.258$ ) (Table 2 ). The prevalence of hypoxemia among the $\mathrm{HbSS}$ patients was $30.25 \%$ compared to $2.7 \%$ amongst the $\mathrm{HbAA}$ (Table 3). The lowest $\mathrm{SpO}_{2}$ recorded among the $\mathrm{HbSS}$ patients was $88 \%$ (Figure 1) and $95 \%$ for the controls respectively (Figure 2).

Table 1 Clinical parameters of HbSS patients and HbAA controls.

\begin{tabular}{|c|c|c|c|}
\hline Parameters & HbSS (N=93) & HbAA (N=48) & P value \\
\hline Age & $23.11 \pm 6.03$ & $25.8 \pm 6.19$ & $0.07 *$ \\
\hline Pulse rate & $88.9 \pm 12.2$ & $82.1 \pm 8.89$ & $0.001 *$ \\
\hline $\mathrm{SpO}_{2}$ & $95.5 \pm 4.1$ & $99.06 \pm 1.14$ & $0.0001 *$ \\
\hline
\end{tabular}

Table 2 Comparison of Mean $\mathrm{SpO}_{2}$ in $\mathrm{HbSS}$ and $\mathrm{HbAA}$ groups based on gender.

\begin{tabular}{|c|c|c|c|}
\hline Subjects & Mean $\mathrm{SpO}_{2}$ & Mean $\mathrm{SpO}_{2}$ & P value * \\
\hline & Males & Females & \\
\hline $\mathrm{HbSS}$ & $95.80 \%$ & $96.10 \%$ & 0.61 \\
\hline $\mathrm{HbAA}$ & $98.90 \%$ & $99.20 \%$ & 0.258 \\
\hline
\end{tabular}

Table 3 Distribution of $\mathrm{SpO}_{2}$ in $\mathrm{HbSS}$ patients and $\mathrm{HbAA}$ control group.

\begin{tabular}{|c|c|c|c|c|c|}
\hline & $\begin{array}{c}\text { Subjects } \\
\text { (HbSS) }\end{array}$ & & & $\begin{array}{c}\text { Controls } \\
\text { (HbAA) }\end{array}$ & \\
\hline $\mathrm{SpO}_{2}$ & $\begin{array}{c}\text { Number of } \\
\text { participants } \\
\text { (93) }\end{array}$ & $\begin{array}{c}\text { Cumulative } \\
\text { \% }\end{array}$ & $\mathrm{SpO}_{2}$ & $\begin{array}{c}\text { Number of } \\
\text { participants } \\
\text { (48) }\end{array}$ & $\begin{array}{c}\text { Cumulative } \\
\%\end{array}$ \\
\hline$<90 \%$ & 6 & 6.5 & $<90 \%$ & 0 & 0 \\
\hline $90-95 \%$ & 22 & 30.1 & $90-95 \%$ & 1 & 2.7 \\
\hline $96-100 \%$ & 65 & 100 & $96-100 \%$ & 48 & 99.3 \\
\hline
\end{tabular}

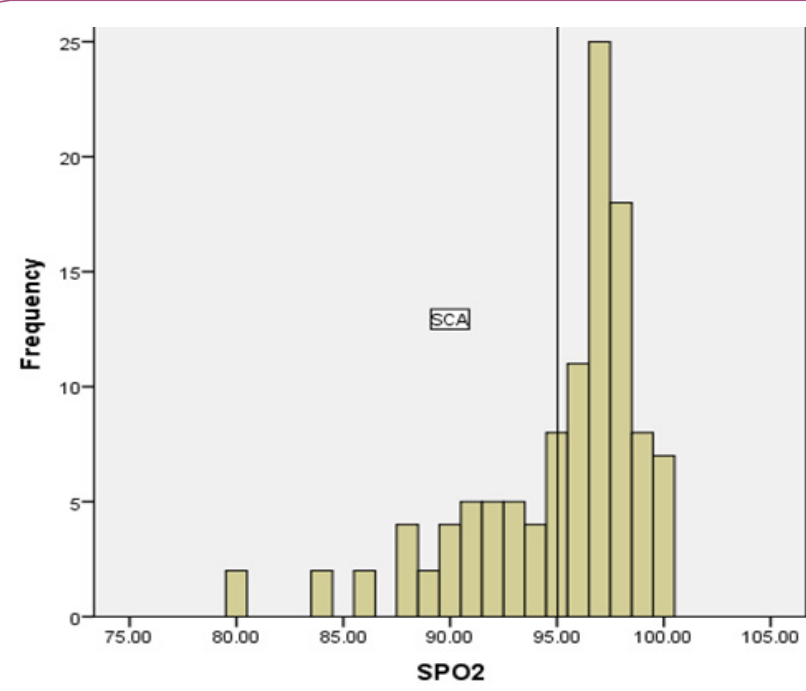

Figure 1 The mean oxygen saturation (vertical line) and its distribution amongst the subjects and control. The lowest $\mathrm{SpO}_{2}$ recorded among the $\mathrm{HbSS}$ patients was $88 \%$.

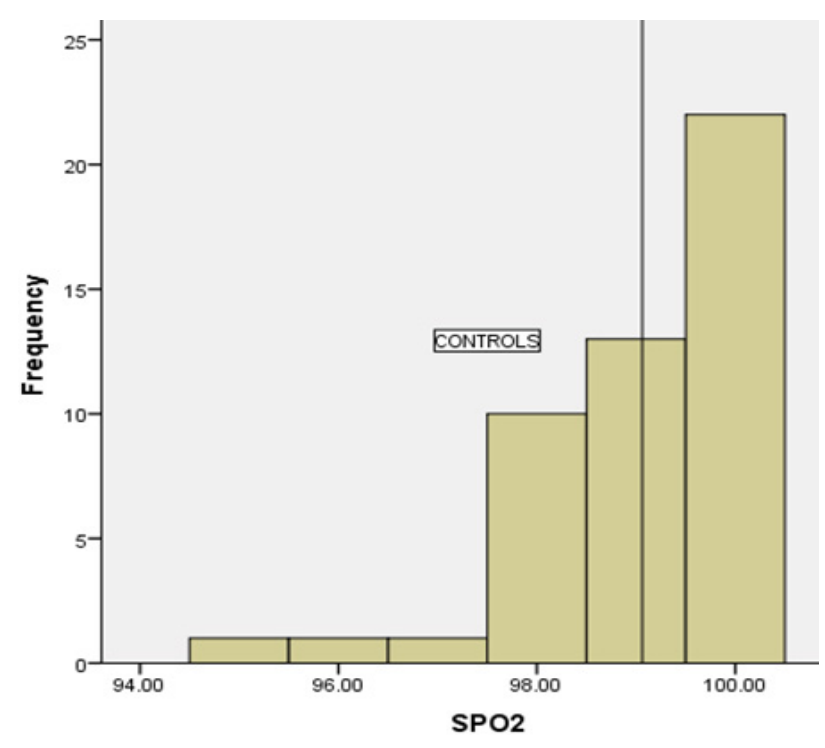

Figure 2 The mean oxygen saturation (vertical line) and its distribution amongst the subjects and control. The lowest $\mathrm{SpO}_{2}$ recorded among the controls was $95 \%$.

\section{Discussion}

We found a prevalence of $30.5 \%$ for hypoxemia in steady state SCA patients using pulse oximetry, a finding similar to earlier 
reports $[9,13]$. Contrary to reports of lower $\mathrm{SpO}_{2}$ levels in male patients with steady state SCA $[11,13]$, our male and female patients had comparable levels of $\mathrm{SpO}_{2}$. Hemoglobin desaturation in patients with steady state SCA has been attributed to several factors. Recurrent episodes of ACS could result in a sequalae of irreversible chronic lung disease, giving rise to defective oxygenation of blood even when in steady state [14]. In addition, the sickle cell hemoglobin S has an inherent property of causing a rightward shift of the oxy-hemoglobin dissociation curve in a bid to enhance oxygen delivery at the tissue level, a trait it shares with raised levels of 2,3-diphosphoglycerate characteristic of SCA $[10,15]$. In keeping with this, the oxygen dissociation curve of 32 clinically well $\mathrm{HbSS}$ patient, $12 \mathrm{HbSC}$ patient and 10 normal control was compared at $70 \mathrm{mmHg}, 80 \mathrm{mmHg}$ and $90 \mathrm{mmHg}$ of $\mathrm{PO}_{2}$. Despite having similar mean level of 2,3 DPG content, the oxygen dissociation curve of $\mathrm{HbSS}$ patient was more right shifted and significantly different when compared with those of the $\mathrm{HbSC}$ group $(p=0.001)$. The authors inferred that $\mathrm{HbS}$ must have an effect on haemoglobin- oxygen affinity that is different from the effect of 2,3 DPG only. The HbSS patients had significantly lower mean resting oxygen saturation, than did patients with $\mathrm{HbSC}$ or the controls [5]. An earlier study had shown that oxygen affinity of $\mathrm{HbSS}$ blood is related to the intra cellular content of $\mathrm{HbS}$ and not 2,3 DPG [14]. All the subjects used for the index study were HbSS and may explain the low level of $\mathrm{SpO}_{2}$ even during steady state. However, hypoxemia is not a universal finding in patients with SCA and this raises some pertinent questions on the significance of hypoxemia in patients with steady state SCA and the best way to manage them, since treatment of apparent hypoxemia based on pulse oximetry in asymptomatic patients carries the deleterious consequences of suppressing erythropoiesis [16].

Pulse oximeter is often use as a surrogate for arterial measurement of oxygen saturation. In patients with normal oxygen dissociation curve, this reading is fairly accurate based on the assumption of a normal P50 of $26.5 \mathrm{mmHg}$ [17]. There have been conflicting reports on the reliability of pulse oximeter in detecting hypoxemia in patients with SCA $[8,14,18]$. Pulse oximeter measures oxyhemoglobin as percentage of functional hemoglobin (oxyhemoglobin and deoxy-hemoglobin), whereas blood gas analysis for oxygen saturation measures it as a percentage of total hemoglobin including carboxy-hemoglobin and met-hemoglobin [14]. In patients with SCA patient undergoing hemolysis, the blood gas measurement may therefore underestimate oxyhemoglobin. Ratkoff et al. showed a wide variability in the oxygen dissociation curve of individuals with SCA and as a result, the $\mathrm{SpO}_{2}$ may be normal for a given partial pressure of oxygen [10]. In addition, the correlation between $\mathrm{SpO}_{2}$ measured by pulse oximetry and value obtained by calculation from blood gas co-oximetry has been shown to be excellent from these studies $[10,14]$. In low and middle income countries where the burden of SCA is very high, arterial blood gas testing is very scarce, hence, pulse oximetry is often relied upon to monitor oxygen saturation $[11,19,20]$.

\section{Conclusion}

Chronic hypoxemia increases the risk of vasculopathy, pulmonary hypertension and cor pulmonale, a life-threatening complication in young adults with SCA $[3,4,16]$. Hemolysis has also been implicated in the pathogenesis of $\mathrm{PH}[16]$. The levels of hemoglobin and reticulocytes, both potent markers of hemolysis, had been shown to be associated with hypoxemia in patients with $\mathrm{HbSS}[13,20]$. Hypoxemia is associated with increased risk of central nervous system (CNS) events in patients with SCA $[21,22]$. This finding formed the premise on which screening and appropriate management of nocturnal hypoxemia was suggested as a safe and effective alternative to prophylactic blood transfusion for primary prevention of CNS events in patients with SCA [5]. Similarly, another study revealed that the odds of having stroke was 1.32 for each $1 \%$ decrease in $\mathrm{SpO}_{2}$, with a further drop in the $\mathrm{SpO}_{2}$ value during an impending stroke [8]. However, even with a normal daytime $\mathrm{SpO}_{2}$, hypoxemia remains a concern in patients with SCA, as it does not exclude nocturnal hypoxia which has been associated with neurological complications [7]. This makes the detection of hypoxemia an important aspect of the management of patients with SCA.

\section{Future Considerations}

The prevalence of hypoxemia in steady state $\mathrm{HbSS}$ patients is high. This finding underscores the importance of monitoring $\mathrm{HbSS}$ patients for prompt detection of hypoxemia, and to institute therapy where necessary. However, despite the association of low oxygen saturation with CNS event and other serious complications, there is still no agreed treatment modality. Previous reports have shown a strong positive correlation between high $\mathrm{HbF}$ and increased $\mathrm{SpO}_{2}[23,24]$. Pashankar et al. reported on the improvement of oxygen saturation following treatment with hydroxyurea (HU). Hydroxyurea increases $\mathrm{HbF}$ level (which has a higher affinity for oxygen than $\mathrm{HbS}$ or $\mathrm{HbA}$ ), and shifts the oxygen dissociation curve to the left which is associated with a high oxygen saturation. There results showed that after a 6 month of treatment, $\mathrm{HU}$ significantly increased oxygen saturation from a baseline of $95.15 \%$ to $98.4 \%$, with the response sustained at 12 months post-treatment. This finding could pave way for the use of $\mathrm{HU}$ in SCA patients with hypoxemia; however, larger academic studies are needed to replicate this report.

\section{Recommendations}

In our study, HbSS patients had a suboptimal mean steady state $\mathrm{SpO}_{2}$ of $95.7 \%$, with the lowest $\mathrm{SpO}_{2}$ of $88 \%$ despite having no evidence of respiratory distress. This underscores the importance of measuring $\mathrm{SpO}_{2}$ during routine evaluation of SCA, as this will provide baseline data against which comparison can be made during acute illnesses, especially when acute chest syndrome is suspected. Baseline $\mathrm{SpO}_{2}$ data may also be useful in prognostication, as well as inform the basis for further evaluation of asymptomatic pulmonary dysfunction e.g. pulmonary hypertension.

\section{Conflict of Interest}




\section{References}

1 Knight J, Murphy TM, Browning I (1999) The lung in sickle cell disease. Pediatr Pulmonol 28: 205-216.

2 Powars DA, Weidman JA, Odom-Maryon TA, Niland JC, Johnson CA (1988) Sickle cell chronic lung disease: prior morbidity and the risk of pulmonary failure. Medicine 67(1): 66-76.

3 Siddiqui AK, Ahmed S (2003) Pulmonary manifestations of sickle cell disease. Postgrad Med J 79: 384-390.

4 Caboot JB, Allen JL (2014) Hypoxemia in sickle cell disease: significance and management. Paediatr Respir Rev 15(1): 17-23.

5 Kirkham FJ, Hewwes DKM, Prengler M, Wade A, Lane R, et al. (2001) Nocturnal hypoxaemia and central-nervous-system events in sicklecell disease. The Lancet 357(9269): 1656-1659.

6 Hargrave DR, Wade A, Evans JPM, Hewes DKM, Kirkham FJ (2003) Nocturnal oxygen saturation and painful sickle cell crises in children. Blood 101(3): 846-848.

7 Halphen I, Elie C, Brousse V, Le Bourgeois M, Allali S, et al. (2014) Severe Nocturnal and Postexercise Hypoxia in Children and Adolescents with Sickle Cell Disease. PLoS ONE 9(5): e97462.

8 Quinn CT, Sargent JW (2008) Daytime steady-state haemoglobin desaturation is a risk factor for overt stroke in children with sickle cell anaemia. Br J Haematol 140(3): 336-339.

9 Homi J, Levee L, Higgs D, Thomas P, Serjeant G (1997) Pulse oximetry in a cohort study of sickle cell disease. Clin lab haematol 19(1):17-22.

10 Rackoff WR, Kunkel N, Silber JH, Asakura T, Ohene-Frempong K (1993) Pulse oximetry and factors associated with hemoglobin oxygen desaturation in children with sickle cell disease. Blood 81: 3422-3427.

11 Chinawa JM, Ubesie AC, Chukwu BF, Ikefuna AN, Emodi IJ (2013) Prevalence of hypoxemia among children with sickle cell anemia during steady state and crises: A cross-sectional study. Nigerian Journal of Clinical Practice 6(1): 2.

12 Bowes WA, Corke BC, Hulka J (1989) Pulse oximetry: A review of the theory, accuracy and clinical applications. Obstet Gynecol 74: 541.

13 Quinn CT, Ahmad N (2005) Clinical correlates of steady-state oxyhaemoglobin desaturation in children who have sickle cell disease. Br J Haematol 131(1): 129-134.
14 Ortiz FO, Aldrich TK, Nagel RL, Benjamin LJ (2012) Accuracy of pulse oximetry in sickle cell disease. Am J Respir Crit Care Med 159: 447-451.

15 Seakins M, Bigs WN, Milner PF, Bertles JF (1973) Erythrocyte Hb-S concentration: An important factor in the low oxygen affinity of blood in sickle cell anemia. J Clin Invest 52: 422.

16 Blaisdell CJ, Goodman S, Clark K (2000) Pulse oximetry is a poor predictor of hypoxemia in stable children with sickle cell disease. Arch Pediatr Adolesc Med 154(9): 900-903.

17 Severinghaus JW, Kelleher JF (1992) Recent developments in pulse oximetry. Anesthesiology 76:1018-1038.

18 Zheng S, Ruiz G, Chan F, Chakravorty S, Bossley C, et al. (2016) Poor agreement between haemoglobin oxygen saturation measured by pulse oximetry and arterialized earlobe blood gas in ambulatory paediatric sickle cell patients. European respiratory Journal 48 : PA1217.

19 Ogah AO, Surat A, Okoruwa AG, Ezeonwumelu JOC, Okolo SN (2012) Oxyhemoglobin saturation in sickle cell anaemic children (steady state) using pulse oxymetry in Jos University Teaching Hospital, Jos, Nigeria. Asian J. Med. Sci 4(5): 161-165.

20 Saad AA, Ibrahim SH, Salih KMA (2016) Oxyhemoglobin saturation in children with sickle cell anemia during steady state and crises using pulse oximetry in Omdurman pediatric hospital- Omdurman, Sudan. Indian Journal of Medical Research and Pharmaceutical Sciences 3(11): 2-6.

21 Sharon E, Cox SE, Makani J, Newton CR, Prentice AM, et al. (2013) Hematological and genetic predictors of daytime hemoglobin saturation in Tanzanian children with and without Sickle cell anemia. ISRN Hematology.

22 Jamie M, Kawadler JM, Fenella J, Kirkham FJ, Clayden JD, et al. ( 2015) White matter damage relates to oxygen saturation in children with sickle cell anemia without silent cerebral infarcts. Stroke 46:17931799.

23 Nkya S, Mgaya J, Urio F, Makubi A, Thein SL, et al. (2017) Fetal hemoglobin is associated with peripheral oxygen saturation in sickle cell disease in Tanzania. EBioMedicine 23: 146-149.

24 Pashankar FD, Manwani D, Lee MT, Green NS (2015) Hydoxyurea improves oxygen saturation in children with sickle cell disease. Journal of Pediatric Hematology/Oncology 37(3): 242-243. 